\section{Curso de}

Comunicação

Social no Brasil:

do Currículo

Mínimo às novas

Diretrizes

\section{Curriculares}

\section{RESUMO}

Neste artigo é analisada a situação atual do Currículo Mínimo do Curso de Comunicação Social, e suas habilitações em Jornalismo, Relações Públicas, Publicidade e Propaganda, conforme Resolução do MEC, No. 002, de 24 de janeiro de 1984.

\section{ABSTRACT}

The objective of this article is to analyse the present curriculum of courses on Social Communication in Brazil and its specific professional fields (Journalism, Public Relations and Advertising) as fixed by Resolution No. 002 of MEC's on January 24, 1984.

PALAVRAS-CHAVE / KEY-WORDS

- Comunicação Social (Social Communication)

- Curriculo (Curriculum)

- Diretrizes Curriculares (Curricular Directives)

\section{Cláudia Peixoto de Moura} Prof. Dra. FAMECOS/PUCRS
ESTE TRABALHO ${ }^{1}$ TEM COMO objetivo analisar a situação atual do Currículo Mínimo do Curso de Comunicação Social, e suas habilitações em Jornalismo, Relações Públicas, Publicidade e Propaganda, fixado pela Resolução $N^{\circ} 002$, de 24 de janeiro de 1984, do Ministério da Educação - MEC, constituído por Matérias ou Disciplinas Obrigatórias e Eletivas do Tronco Comum e por uma Parte Específica, na qual outras Matérias ou Disciplinas também são obrigatórias, e as propostas contidas nas novas diretrizes estabelecidas para a formação acadêmica nas áreas.

Analisamos o passado, o presente e o futuro da formação nas habilitações mais demandadas da Comunicação Social. Para tanto, fizemos um resgate da documentação dos currículos mínimos estabelecidos pelos Pareceres e Resoluções, emitidos pelo MEC, às novas diretrizes curriculares propostas pela Comissão de Especialistas de Ensino de Comunicação Social - CEE/COM, a partir da indicação da Lei $n^{\circ}$ 9.394/96 - Lei de Diretrizes e Bases da Educação Nacional - LDB, em seu Art. 53, inciso II. Na verdade, o estudo se caracteriza por uma sistematização de informações, por uma documentação baseada em determinados aspectos considerados relevantes para esclarecimentos a respeito do assunto.

A legislação específica do assunto permitiu comparações, onde observamos semelhanças e diferenças quanto à questão curricular em Comunicação 
Social. Foram cinco currículos mínimos implantados (Parecer $n^{\circ}$ 323/62, Parecer $n^{\circ}$ 984/65, Resolução $n^{\circ}$ 11/69, Resolução $n^{\circ} 3 / 78$, Resolução $n^{\circ} 2 / 84$ ), que podem ser classificados, conforme o Parecer $n^{\circ}$ 480/83, nas fases: clássico-humanística (até a segunda metade da década de 60), científico-técnica (década de 60), críticoreflexiva (década de 70), e de crise de identidade (década de 80).

As fases referem-se ao ensino da teoria e das práticas profissionais enfocadas nos cursos. Assim, podemos fazer as seguintes associações:

- a fase clássico-humanística está associada a um enfoque nas questões humanas;

- a fase científico-técnica está associada a um enfoque nas atividades específicas das áreas profissionais;

- a fase crítico-reflexiva está associada a um enfoque crítico aos condicionamentos sociais;

- a fase da crise de identidade está associada ao fato de existir um currículo formal, impedindo novos projetos de curso.

Desde 1962 existe um currículo mínimo conduzindo esta formação, e na Resolução $n^{\circ}$ 02/84 há matérias/disciplinas com as respectivas ementas atendendo uma estrutura previamente determinada pelo órgão federal, voltadas às funções e atividades profissionais. Um problema da questão curricular está na condução das disciplinas na sala de aula, pelo professor. Neste aspecto, concordamos com Torquato (1979) que aponta o corpo docente como o responsável pelo currículo. Até porque, na nossa opinião, as disciplinas poderiam ser ministradas a partir do perfil desejado para o egresso de cada instituição de ensino.

A preocupação com o corpo docente também foi manifestada por Braga (1992), que discute o perfil do professor para a área de Comunicação. $O$ conhecimento de teorias ou a experiência profissional são perspectivas concorrentes para selecionar o quadro docente dos cursos. Esta divisão entre a teoria e a prática ocorre na maioria das escolas, correspondendo, de forma equivocada, ao Tronco Comum e à Parte Especializada do currículo mínimo. A visão teórica, voltada a uma ciência social, e a visão das necessidades do mercado, vinculadas à reprodução técnica, costumam determinar a organização curricular, e os professores encontram-se enquadrados em uma destas perspectivas.

Interessadas em obter informações sobre a situação atual do currículo mínimo, algumas instituições acadêmicas realizaram pesquisas a respeito da Resolução $n^{\circ}$ 02/ 84. Os resultados revelam que:

- a maioria das escolas de Comunicação Social pesquisadas pela Executiva Nacional dos Estudantes de Comunicação Social - ENECOS (1995) oferece em seus currículos as disciplinas: Teoria e Método da Pesquisa em Comunicação, Psicologia, Economia, Cultura Brasileira, História da Comunicação, Antropologia Cultural, Estética e Cultura de Massas.

- os egressos, das três habilitações, pesquisados pelo Núcleo de Pesquisa do Mercado de Trabalho em Comunicações e Artes - NUPEM (1998) avaliaram os Projetos Experimentais e/ou Trabalhos de Conclusão de Curso como mais adequados ao exercício profissional, em detrimento dos conteúdos humanísticos, dos específicos e das práticas laboratoriais. Porém, para o desempenho profissional os conteúdos teóricos e técnicos são igualmente importantes na opinião da maioria. E para o exercício profissional mais atualizado é necessário incluir disciplinas técnicas e excluir as disciplinas do tronco comum da grade curricular.

- a maioria dos representantes dos Cursos de Comunicação Social pesquisados pela Associação Brasileira de Escolas de Comunicação Social - ABECOM (1996) pensa que a Resolução $n^{\circ}$ 02/84 deve continuar normativa, mas 
permitir uma liberdade na concepção curricular para propiciar adaptações às diferenças regionais.

As comunidades acadêmica e profissional foram consultadas para verificar quais as proposições para um novo currículo. Realizamos uma pesquisa especificamente para contemplar os aspectos abordados no trabalho. Por ocasião do "Fórum do Movimento pela Qualidade de Ensino" ocorrido em Recife, dia 10 de setembro de 1998, realizamos um levantamento da posição dos professores participantes do evento a respeito da questão curricular. A opinião dos docentes dos Cursos de Comunicação Social demonstra que:

- se houver uma mudança curricular, não deverá ser conservada a estrutura modular para o Curso, exigida pela Resolução $n^{\circ}$ 02/84 (MEC), para a maioria;

- a duração mínima considerada ideal para a conclusão do Curso foi de três (3) anos e a duração máxima indicada foi de cinco (5) anos;

- a carga horária mínima considerada ideal para a conclusão do Curso obteve duas propostas: uma de 2.000 horas-aula e outra de 2.700 horas-aula;

- cinco (5) matérias ou disciplinas obrigatórias ${ }^{2}$ do Tronco Comum deverão ser conservadas, das seis (6) elencadas na Resolução $n^{\circ}$ 02/84 (MEC). Apenas "Comunicação Comparada" não deverá ser conservada no novo currículo;

- quatro (4) matérias ou disciplinas eletivas $^{3}$ do Tronco Comum deverão ser conservadas, das 21 indicadas na resolução;

- oito (8) matérias ou disciplinas da Parte Específica da Habilitação em Jornalismo ${ }^{4}$ deverão ser conservadas, das nove (9) da Resolução $n^{\circ}$ 02/84 (MEC). Apenas "Preparação e revisão de Originais, Provas e Videotexto" não deverá ser conservada no novo currículo;

- todas as sete (7) matérias ou disciplinas da Parte Específica da Habilitação em Relações Públicas ${ }^{5}$, da resolução, deverão ser conservadas;

- oito (8) matérias ou disciplinas da Parte Específica da Habilitação em Publicidade e Propaganda ${ }^{6}$ deverão ser conservadas, das nove (9) constantes na Resolução $n^{\circ}$ 02/84 (MEC). Apenas "Estatística" não deverá ser conservada no novo currículo;

- as sugestões de matérias para compor um novo currículo, nas três habilitações, são: Novas Tecnologias em Comunicação/Multimídia, Comunicação e Cultura, Comunicação Organizacional;

- houve concordância com o Currículo Mínimo do Curso de Comunicação Social, no que tange à indicação de matérias ou disciplinas da Resolução $n^{\circ}$ 02/84 (MEC), tanto para o Tronco Comum como para a Parte Específica das Habilitações, embora seja questionada a obrigatoriedade. Porém, as sugestões de matérias ou disciplinas já contempladas na Resolução demonstram um desconhecimento da legislação;

- não houve concordância com as normatizações estabelecidas na Resolução quanto à estrutura modular do curso e a sua duração. E sobre a carga horária mínima, houve omissão, talvez pela falta de conhecimento para emitir uma opinião a respeito do assunto.

Realizamos também entrevistas, nas quais as opiniões de representantes de entidades relacionadas ao estudo foram registradas. As entidades selecionadas possuem abrangência nacional, representam a classe profissional nas três áreas que têm relação com o trabalho (Jornalismo, Relações Públicas, Publicidade e Propaganda), representam as instituições de ensino, com Cursos de Comunicação Social, em nível de graduação, e em nível de pós-graduação, representam os pesquisadores e os estudantes da área da Comunicação. A partir das respostas dos entrevistados observamos as seguintes tendências gerais: 
- além do caráter social das profissões, os aspectos convergentes estão relacionados a um campo teórico comum na área da Comunicação;

- a formação deve privilegiar uma reflexão sobre a atuação do profissional, suas práticas, e sobre os problemas emergentes da sociedade, estabelecendo a relação entre o ensino e o mercado de trabalho na área, que está exigindo habilitações novas, áreas híbridas;

- a preocupação com a qualificação do ensino na área deve ser uma das funções das entidades, devido ao fato desta questão repercutir nas profissões;

- a Resolução $n^{\circ}$ 02/84 é considerada ampla, com orientações superadas que empobrecem a área por dificultar uma reflexão adequada na elaboração dos projetos pedagógicos;

- entre as sugestões dadas para as novas diretrizes curriculares estão: liberação, flexibilização dos currículos; projetos interdisciplinares; diversidade de projetos acadêmicos/pedagógicos; valorização dos aspectos regionais; indicação de 4 ou 5 conteúdos; indicação das Ciências Sociais como Psicologia, História, Filosofia, Antropologia, Sociologia para compor os conteúdos; indicação de disciplinas de análise do próprio mercado (do fazer da profissão); suporte nas novas tecnologias; equilíbrio entre matérias teóricas e práticas.

Novas diretrizes curriculares para - Curso de Comunicação Social foram propostas no documento oficial da CEE/ COM, que contou com três versões e a influência do Seminário Nacional das Diretrizes Curriculares do Ensino de Jornalismo, ocorrido nos dias 24 e 25 de abril de 1999, na cidade de Campinas, São Paulo, realizado pela entidade nacional dos jornalistas, que teve uma atuação importante quanto à movimentação pela qualidade de ensino. No entanto, a área de Jornalismo pressionou para não se configurar mais como uma habilitação do curso de Comunicação Social, e sim um Curso Superior de Jornalismo, totalmente desvinculado da situação anterior.

Esta modificação não foi incorporada ao documento oficial, porém os jornalistas estão divididos a respeito desta questão e têm se manifestado sobre o fato em periódicos e via e-mail. Acreditamos que este episódio influenciou o encaminhamento das novas diretrizes e o futuro do ensino de Jornalismo e de outras habilitações da Comunicação Social.

Algumas sugestões, tanto dos docentes pesquisados como dos representantes de entidades, para 0 novo currículo estão contempladas no documento final elaborado pela comissão do MEC. As indicações que compõem o referido documento revelam áreas a serem ministradas nos cursos, diferenciandose do currículo mínimo relacionado às matérias/disciplinas vinculadas às funções específicas das profissões.

$$
\text { As matérias e disciplinas }
$$
estabelecidas no currículo mínimo estão atreladas às legislações profissionais. Os resultados das pesquisas realizadas pelas instituições, das posições dos docentes pesquisados e dos entrevistados revelaram que existe uma aceitação dos conteúdos atualmente oferecidos pelas escolas e uma rejeição às normas que se caracterizam pela obrigatoriedade. Evidentemente, esta aceitação poderia ser maior se as matérias e disciplinas fossem mais adequadas à realidade atual.

As atividades específicas indicadas na legislação profissional de Jornalismo, de Relações Públicas e de Publicidade e Propaganda foram levantadas, possibilitando o estabelecimento de convergências entre elas. Jornalismo e Relações Públicas apresentaram maior índice de convergência. As mesmas atividades profissionais foram confrontadas com o elenco de matérias/disciplinas relativas à parte específica das três habilitações do Curso de Comunicação Social. Isto permitiu verificar a coerência do 
ensino das técnicas em relação ao exercício das profissões, cujo aproveitamento é maior em Publicidade e Propaganda.

Nos aspectos convergentes das profissões de Jornalismo, Relações Públicas, Publicidade e Propaganda, o perfil, competências e habilidades são comuns, vinculados à comunicação. Nos aspectos divergentes, o perfil, competências e habilidades são diferenciados, vinculados às especificidades das habilitações. Assim, as convergências estão relacionadas às competências gerais e as divergências às competências específicas por habilitação. $E$, as habilitações trabalham com a informação de forma diferenciada.

Quanto às escolas, estas devem detalhar seus perfis de acordo com suas características regionais. Não definir perfil implica em um perfil indefinido. Cada curso deve definir seu perfil conforme suas preferências. O perfil, competências e habilidades, devem estar vinculados às características regionais e institucionais. Igualmente o docente deve ter o perfil adequado aos conteúdos, procedimentos e objetivos das disciplinas que ministra.

As matérias/disciplinas indicadas na Resolução $n^{\circ} 02 / 84$ podem ser classificadas nas seguintes áreas do conhecimento: Ciências Humanas, Ciências Sociais Aplicadas, Lingüística, Letras e Artes. Convém ressaltar que estas áreas são citadas pelas pessoas envolvidas com o Ensino da Comunicação, para fundamentar a formação profissional. Estas áreas abrigam também os conteúdos registrados nas Diretrizes Curriculares, que não prevêem disciplinas pois não é esta a finalidade. De acordo com o documento oficial, o currículo não é mais um conjunto de disciplinas, mas sim um conjunto de atividades. $\mathrm{E}$ as diretrizes são caminhos, recomendações para as instituições de ensino.

É importante retomarmos um trecho do Parecer $n^{\circ} 480 / 83$, relativo ao último currículo mínimo adotado. A elaboração do currículo da Resolução $n^{\circ}$ 02/84 teve como base as seguintes diretrizes: ${ }^{7}$

- "incorporar as três áreas de conhecimento necessárias à formação: Ciências Sociais, Ciências da Comunicação e da Linguagem e Filosofia e Arte";

- "respeitar o princípio de flexibilidade do ensino";

- "ampliar, fortalecer e especificar as matérias técnico-laboratoriais, com objetivo de reforçar as atividades de caráter prático, entendendo como tal não a prática meramente imitativa, mas a prática acompanhada da reflexão crítica sobre seu significado";

- "recomendar aos cursos que organizem as atividades em torno de projetos, a fim de permitir a integração curricular horizontal e vertical e de se evitar a fragmentação do ensino";

- "recomendar o rompimento da tendência à divisão rígida entre matérias teóricas e práticas";

- "exigir que os cursos se equipem da maneira mais completa possível";

- incorporar ao currículo novas matérias decorrentes do desenvolvimento de novas áreas dentro da Comunicação;

- "recomendar a articulação de uma relação orgânica entre ensino, pesquisa e extensão";

- "fortalecer o ensino de Redação em Língua Portuguesa".

Lendo estas diretrizes podemos pensar que foram estabelecidas em 1999, para possibilitar uma formação adequada na área da Comunicação Social. Porém, há mais de 16 anos elas foram traçadas, embasando um currículo mínimo. Se desconsiderarmos a obrigatoriedade inerente à resolução, podemos afirmar que as diretrizes constantes no parecer estão em sintonia com a atualidade, pois indicam áreas do conhecimento, flexibilidade para o ensino, matérias técnico-laboratoriais para atividades práticas com reflexão crítica, organização de projetos de curso para integrar o currículo de forma horizontal e 
vertical, divisão equivocada entre teoria e prática, equipamentos para os cursos, incorporação de novas matérias quando necessário, articulação entre ensino, pesquisa e extensão, ensino de Redação. Todos estes itens compõem o documento oficial da CEE/COM para as novas diretrizes curriculares.

O Currículo Mínimo do Curso de Comunicação Social serve de base para as propostas contidas nas novas diretrizes estabelecidas na medida em que há possibilidade de experimentação. Até 1999, todos os cursos deveriam seguir o currículo mínimo, ao passo que, a partir de agora, todos os cursos podem, ou não, seguir as normas do passado. Pelas novas diretrizes curriculares, um determinado curso pode continuar adotando as matérias/disciplinas do currículo mínimo e, ao longo do tempo, fazer adaptações para garantir maior qualidade ao seu ensino, considerando as modificações tecnológicas, sociais e as especificidades das regiões. Isto porque a instituição tem liberdade para decidir sobre seus conteúdos.

$\mathrm{Na}$ opinião dos docentes pesquisados, a maioria das matérias/disciplinas que compõem a Resolução deverá ser conservada, principalmente no que diz respeito à Parte Específica das Habilitações do Curso. Para os representantes da comunidade profissional, a Resolução é ampla e superada por dificultar a elaboração de projetos pedagógicos. Já que não existe mais a obrigatoriedade de uma estrutura curricular nacional, é claro que projetos pedagógicos diferenciados acontecerão em todo o Brasil. Contudo, não é possível eliminar totalmente os conteúdos definidos em 1984, porque atendem as atividades profissionais de Jornalismo, Relações Públicas, Publicidade e Propaganda, determinadas pela legislação específica.

Na Resolução $n^{\circ}$ 02/84 são indicadas matérias ou disciplinas, cujos conteúdos foram estabelecidos por um ementário, e nas novas diretrizes curriculares há presença de áreas do conhecimento, que possibilitam a incorporação de novos coriteúdos quando o currículo necessitar de atualizações. Esta forrna de estruturar o currículo pode ser ilustrada da seguinte maneira:

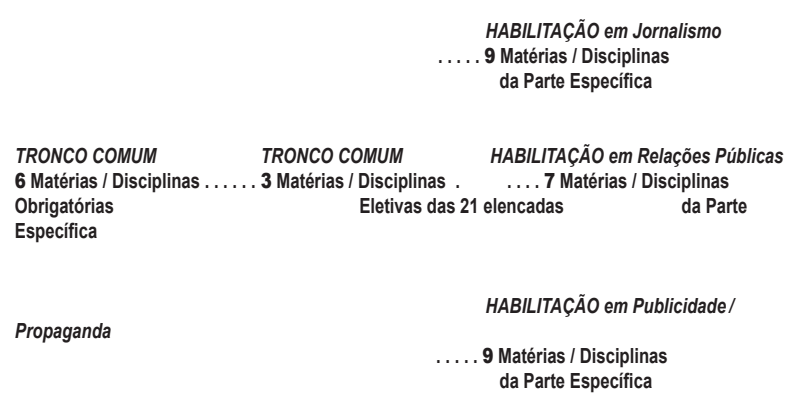

Figura nº 1 - Currículo Mínimo do Curso de Comunicação Social

\begin{tabular}{|c|c|c|c|}
\hline CONTEÚDOS & CONTEÚDOS & CONTEÚDOS & CONTEÚDOS \\
\hline BÁSICOS & BÁSICOS & BÁSICOS & BÁSICOS \\
\hline Conhecimentos & Conhecimentos & Conhecimentos & Conhecimentos \\
\hline Técnico-Conceituais & $\begin{array}{l}\text { Analiticos e } \\
\text { Informativos s/ } \\
\text { a Atualidade }\end{array}$ & $\begin{array}{l}\text { de Linguagens } \\
\text { Técnicas e Tecnologias } \\
\text { Midiáticas }\end{array}$ & Ético-Politicos \\
\hline CONTEÚDOS & CONTEÚDOS & CONTEÚDOS & CONTEÚDOS \\
\hline ESPECIFIICOS & ESPECÍFICOS & ESPECÍFICOS & ESPECÍFICOS \\
\hline Parte Geral & Parte Geral & Parte Geral & Parte Geral \\
\hline Parte Específica & Parte Especifica & Parte Específica & Parte Especifica \\
\hline
\end{tabular}

Figura $n^{0} 2$ - Diretrizes Curriculares para o Curso de Comunicação Social

Como podemos observar, existe uma divisão entre as matérias/disciplinas do Tronco Comum e da Parte Específica das habilitações, na Resolução $n^{\circ}$ 02/84. Já nas Diretrizes Curriculares, os Conteúdos Básicos e Específicos estão relacionados a áreas do conhecimento, nas quais a teoria e a prática podem ser abordadas de forma simultânea.

$\mathrm{Na}$ nossa opinião, a maioria das matérias/disciplinas da Resolução $n^{\circ}$ 02/84 será conservada pelos cursos de Comunicação no Brasil em um novo currículo. Provavelmente, algumas disciplinas voltadas às novas tecnologias serão incluídas no currículo organizado pelas escolas. Pode ser que, a partir de agora, o embasamento teórico e as técnicas características das habilitações 
sejam abordados de forma simultânea. Isto já é permitido na referida resolução, mas normalmente as escolas dividem - Tronco Comum da Parte Específica das Habilitações, ministrando disciplinas teóricas da Comunicação nos dois primeiros anos e disciplinas técnicas específicas nos dois últimos anos dos cursos. Acreditamos que esta divisão tenderá a desaparecer.

A opinião das comunidades acadêmica e profissional aqui representadas é favorável a vários aspectos da organização curricular. Os resultados do estudo definem como desfavorável a obrigatoriedade imposta pela legislação, para o funcionamento de um Curso de Comunicação Social. Acreditamos que o elenco de matérias/ disciplinas assegurado na Resolução $n^{\circ} 02 /$ 84 passará a ser utilizado como parâmetro para os novos currículos, observando a flexibilidade que será uma característica dominante dos projetos pedagógicos da instituições de ensino. E, a elaboração destes projetos deverá estar de acordo com o perfil desejado para o egresso do curso, sempre considerando suas competências e habilidades para enfrentar o mercado de trabalho.

Apesar das críticas à Resolução $n^{\circ}$ 02/84, devido às imposições do Estado, os conteúdos curriculares determinados são necessários para a formação profissional. Com isso, percebemos que a busca pela qualidade do ensino em Comunicação Social está atrelada ao conhecimento e qualificação dos professores. Com a nova LDB, houve uma modificação no estrutura do ensino no País. Os currículos mínimos impostos pelo Estado deixam de existir, determinando uma abertura por parte do governo federal e uma responsabilidade pela qualidade do ensino por parte das instituições educacionais.

As Diretrizes Curriculares para o Curso de Comunicação Social foram traçadas para qualificar o ensino na área. A responsabilidade é de vários segmentos que discutiram a questão, com base nos fatos do passado e presente. A experiência adquirida nesta trajetória vai permitir novos avanços rumo a um futuro onde a competência do egresso do curso irá prevalecer.

Passado, presente e futuro estão vinculados e vão caracterizar os novos projetos pedagógicos dos Cursos de Comunicação Social.

Acreditamos que os novos projetos serão elaborados a partir de estruturas curriculares adequadas às necessidades e experiências dos estudantes de cada região. É provável que as instituições de ensino promovam debates sobre o assunto, nos quais docentes e discentes participarão das decisões. A construção do currículo será diferenciada nas escolas, porém os conteúdos inerentes às atividades profissionais deverão ser abordados. Cabe aos conteúdos indicados explicitar o ser e fazer das profissões de jornalista, de relações públicas e de publicitário, sendo esta uma preocupação que observamos no currículo mínimo e nas novas diretrizes curriculares da Comunicação Social .

Notas

1 Trabalho apresentado no GT FORMAÇÃO PROFISSIONAL, ocorrido no X ENCONTRO LATINO-AMERICANO DE FACULDADES DE COMUNICAÇÃO SOCIAL, realizado pela Federación Latinoamericana de Facultades de Comunicación Social - FELAFACS, Associação Brasileira de Escolas de Comunicação Social - ABECOM, e Escola de Comunicações e Artes da Universidade de São Paulo - ECA/USP. São Paulo, outubro de 2000. 0 presente texto é parte da Tese de Doutorado defendida em julho de 2000, na ECA/USP.

2 Teoria da Comunicação, Sociologia (Geral e da Comunicação), Filosofia, Língua Portuguesa - Redação e Expressão Oral, Realidade Sócio-Econômica e Política Brasileira.

3 Teoria e Método de Pesquisa em Comunicação, Psicologia, História da Comunicação, Cultura Brasileira. 
4 Legislação e Ética do Jornalismo, Língua Portuguesa - Redação e Expressão Oral, Fotojornalismo, Radiojornalismo, Técnica de Reportagem, Entrevista e Pesquisa Jornalística, Telecinejornalismo, Planejamento Gráfico em Jornalismo, Edição.

5 Planejamento de Relações Públicas, Língua Portuguesa Redação e Expressão Oral, Teoria e Pesquisa de Opinião Pública, Técnicas de Relações Públicas, Legislação e Ética de Relações Públicas, Técnica de Comunicação Dirigida, Administração e Assessoria de Relações Públicas.

6 Língua Portuguesa - Redação Publicitária, Planejamento de Campanha, Produção Publicitária em Rádio, Televisão e Cinema, Produção Gráfica, Mídia, Ética e Legislação Publicitária, Mercadologia, Administração em Publicidade e Propaganda.

7 Parecer n $n^{0}$ 480/83, sub-item 2.3.2.

\section{Referências}

BRAGA, José Luiz. "A Formação de Professores para a Comunicação". In: KUNSCH, Margarida M. Krohling (org.) $O$ Ensino de Comunicação: análises, tendências e perspectivas futuras. São Paulo: ABECOM: ECA/USP, 1992.

LJUBTSCHENKO, Valentina; e VALENTE, Nelson (orgs.). Diretrizes e Bases da Educação Nacional: Lei Darcy Ribeiro: fundamentos legais. São Paulo: EDICON, 1997.

MOURA, Cláudia Peixoto de. "Relações Públicas X Jornalismo - aspectos convergentes". Trabalho apresentado no GT Relações Públicas, no XX Congresso Brasileiro de Ciências da Comunicação, da Sociedade Brasileira de Estudos Interdisciplinares da Comunicação - INTERCOM. Santos, SP: setembro de 1997.

SANTOS, Reinaldo. Vade-Mécum da Comunicação. 8. ed. Rio de Janeiro: Edições Trabalhistas, 1989.

TORQUATO, Gaudêncio. "Formação do Jornalista". In MELO, José Marques de; FADUL, Anamaria; e SILVA, Carlos Eduardo Lins da (coords.) Ideologia e Poder no Ensino de Comunicação. São Paulo: Cortez \& Moraes: INTERCOM, 1979.

\section{Documentos da Área de Comunicação Social}

IV CONGRESSO BRASILEIRO DE ENSINO DE COMUNICAÇÃO. Taubaté: ABECOM-UNITAU, de 03 a 06 de julho de 1996.

DIRETRIZES CURRICULARES DA ÁREA DA COMUNICAÇÃO SOCIAL. Brasília: CEE/COM (Estudo Preliminar e Parcial - $1^{a}$ versão).

DIRETRIZES CURRICULARES DA ÁREA DA COMUNICAÇÃO E SUAS HABILITAÇÕES. Brasília: CEE/ COM (2 versão).

DIRETRIZES CURRICULARES DA ÁREA DA COMUNICAÇÃO E SUAS HABILITAÇÕES. Brasilia: CEE/ COM (Documento Final).

ENECOS - Executiva Nacional dos Estudantes de Comunicação Social. "Análise Descritiva das Escolas de Comunicação Social do Brasil". Rio de Janeiro: UERJ, [1995].

LOPES, Maria Immacolata Vassallo de (coord.). Campo Profissional e Mercados de Trabalho em Comunicação no Brasil. São Paulo: NUPEM - ECA/USP, abril de 1998 (Relatório Nacional em disquete).

PROPOSTA DE DIRETRIZES CURRICULARES DA ÁREA DE COMUNICAÇÃO E HABILITAÇÕES ESPECÍFICAS. Campinas: Seminário Nacional de Diretrizes Curriculares do Ensino de Jornalismo, 24 e 25 de abril de 1999.

\section{Documentos Legais}

MEC/CFE. Documenta (10): 76-79. Rio de Janeiro, dez. 1962.

MEC/CFE. Documenta (50): 69-70. Rio de Janeiro, abril 1966.

MEC/CFE. Documenta (105): 99-117. Rio de Janeiro, set. 1969.

MEC/CFE. Documenta (109): 282. Rio de Janeiro, dez. 1969.

MEC/CFE. Documenta (198): 44-55. Brasília, maio 1977. 
MEC/CFE. Documenta (206): 89-99. Brasília, jan. 1978.

MEC/CFE. Documenta (212): 712-718. Brasília, jul. 1978.

MEC/CFE. Documenta (217): 143. Brasília, dez. 1978.

MEC/CFE. Documenta (218): 372. Brasília, jan. 1979.

MEC/CFE. Documenta (274):81-109. Brasília, out. 1983.

MEC/CFE. Documenta (278): 209-211. Brasília, fev. 1984.

\section{Entrevistas}

CORRÊA, Tupã Gomes. Representante da ABECOM Associação Brasileira de Escolas de Comunicação Social. Entrevista concedida em novembro de 1998.

FRAGA, Vitor. Representante da ENECOS - Executiva Nacional dos Estudantes de Comunicação Social. Entrevista concedida em dezembro de 1998.

GRACIOSO, Francisco. Representante da APP - Associação dos Profissionais de Propaganda. Entrevista concedida em outubro de 1998.

HERZ, Daniel. Representante da FENAJ - Federação Nacional dos Jornalistas. Entrevista concedida em novembro de 1998.

QUEIROZ, Adolpho Carlos Françoso. Representante da INTERCOM - Sociedade Brasileira de Estudos Interdiscipli-nares da Comunicação. Entrevista concedida em setembro de 1998.

RUBIM, Antonio Albino Canelas. Representante da COMPÓS Associação Nacional de Programas de Pós-Graduação em Comunicação. Entrevista concedida em fevereiro de 1999.

ZAPATA, Júlio. Representante do CONFERP - Conselho Federal de Profissionais de Relações Públicas. Entrevista concedida em setembro de 1998.

\section{Páginas na Internet}

- http://www.cnpq.br/forms 